\title{
INFLUÊNCIA DA QUALIDADE DA ÁGUA EM EXPERIMENTO CONDUZIDO EM VASOS
}

Thaís Soto Boni ${ }^{1}$, Kátia Luciene Maltoni ${ }^{2}$, Diego Gonçalves Feitosa ${ }^{3}$, Ana Maria Rodrigues Cassiolato $^{2}$

${ }^{1}$ Mestranda em Agronomia pela Faculdade de Engenharia - UNESP Campus de Ilha Solteira (SP). E-mail: thais.sboni@gmail.com

${ }^{2}$ Docente do Departamento de Fitossanidade, Engenharia Rural e Solos da Faculdade de Engenharia - UNESP Campus de Ilha Solteira (SP).

${ }^{3}$ Mestre em Agronomia pela Faculdade de Engenharia - UNESP Campus de Ilha Solteira (SP).

RESUMO: Em experimentos conduzidos em vasos e molhados com água de abastecimento público, o solo pode apresentar modificações nas propriedades químicas. As alterações ocorrem em função da qualidade e quantidade da água, comprometendo, por vezes, os resultados. O objetivo deste trabalho foi avaliar as alterações ocorridas na fertilidade do solo, em experimentos conduzidos em vasos, em condições protegidas, após molhamento com água de abastecimento público. O experimento foi conduzido por oito meses, em Latossolo Vermelho Distrófico, textura argilosa, coletado na camada de 0-0,20 m, peneirado ( $2 \mathrm{~mm}$ ) e acondicionado em vasos (2 L). Para o molhamento foi utilizado dois tipos de água (água purificada em deionizador e água de abastecimento público de Ilha Solteira - SP), empregando quatro volumes de água (0, 200, 400 e $600 \mathrm{~mL})$, com três repetições. Durante o período experimental (240 dias), o solo foi amostrado a cada 60 dias para as análises de fertilidade. A água fornecida pelo setor público apresentou teores de cálcio $\left(\mathrm{Ca}^{2+}\right)$, magnésio $\left(\mathrm{Mg}^{2+}\right)$ e fósforo (P) de $81 ; 29$; e 1,19 $\mathrm{mg} \mathrm{L}^{-1}$ de água, respectivamente. Os resultados mostraram que a qualidade da água interferiu na fertilidade do solo, produzindo incrementos em $\mathrm{P}, \mathrm{Ca}^{2+}, \mathrm{Mg}^{2+}$ e $\mathrm{pH}$. Os molhamentos possibilitaram a lixiviação do $\mathrm{K}^{+}$do solo, reduzido em 32-38\%, em condições extremas ( $9.240 \mathrm{~mm}$ da lâmina d'água), o que equivale a 8 anos de chuvas em uma região com precipitação média anual de $1.155 \mathrm{~mm}$.

Palavras-chave: Lixiviação de $\mathrm{K}^{+}$. Fertilidade. Cultivo protegido.

\section{INFLUENCE OF WATER QUALITY ON EXPERIMENT CONDUCTED IN VASES}

ABSTRACT: The soil in experiments conducted in vases and watered with the public water supply may exhibit chemical changes, whose intensity may vary with the water quality and quantity, compromising the assessments to be made. The aim of this research was to evaluate changes in soil fertility, in experiment conducted in vases, and watered, with water from public supply, under protected conditions. The experiment was conducted over eight months, in an Oxisol, with clayey texture. The soil was collected from $0-0.20 \mathrm{~m}$ deep, sieved $(2 \mathrm{~mm})$ and placed in vases $(2 \mathrm{~L})$, the vases were watered with two types water (purified water by reverse osmosis system and water provided by public supply sector from Ilha Solteira - SP), four watered volumes were used (0, 200, 400 and $600 \mathrm{~mL})$, with three 
replications. Soil fertility analyzes were held every 60 days throughout the experimental period (240 days). The water supplied by the public sector showed calcium $\left(\mathrm{Ca}^{2+}\right)$, magnesium $\left(\mathrm{Mg}^{2+}\right)$ and phosphorus (P), as 81; 29; and 1,19 $\mathrm{mg} \mathrm{L}^{-1}$ water, respectively. The results showed that water quality interfered in soil fertility, which produced increments in $\mathrm{P}$, $\mathrm{Ca}^{2+}, \mathrm{Mg}^{2+}, \mathrm{pH}$, and $\mathrm{K}^{+}$leaching, which was reduced $32-38 \%$ in extreme conditions $(9240$ $\mathrm{mm}$ of water lamina), which is equivalent to 8 years of rainfall in a region with $1,155 \mathrm{~mm}$ annual average of precipitation.

Key words: $\mathrm{K}^{+}$leaching. Fertility. Protected cultivation.

\section{INTRODUÇÃO}

O cultivo protegido de vegetais, flores e frutas tem se tornado cada vez mais popular em muitos países (CHUNG et al., 2015). No Brasil, o plantio protegido cresceu $400 \%$ em duas décadas, sendo mais utilizado para produção de mudas, hortaliças e frutas (SILVA; SILVA; PAGIUCA, 2014). De acordo com o Comitê Brasileiro de Desenvolvimento e Aplicação de Plásticos na Agricultura, o Brasil tem atualmente 22 mil ha de estufas, dados de 2014, tendo o estado de São Paulo mais de 11 mil ha de estufas, utilizadas na produção de flores, hortaliças, mudas para citricultura, café, reflorestamento e recuperação de matas ciliares (LAGE, 2011).

O menor custo do cultivo protegido, em relação às tradicionais casas de vegetação, gerou uma demanda crescente por pesquisas, as quais são, em grande parte, conduzidas em vasos. No entanto, estas nem sempre consideram a qualidade da água utilizada, pois dependendo do foco da pesquisa este fator pode, inicialmente, não se mostrar importante, permitindo o uso de água de abastecimento público.

No município de Ilha Solteira-SP, local de condução do experimento, a água de abastecimento público vem de 15 poços artesianos, perfurados com profundidades variando de 30 a $80 \mathrm{~m}$, com vazões de 50 a $120 \mathrm{~m}^{3} \mathrm{~h}^{-1}$ e pH=8,0 (ILHA SOLTEIRA, 2015).

Este valor de $\mathrm{pH}$ pode ser explicado pela ocorrência na região de águas bicarbonatadas cálcicas ou magnesianas, principalmente (CAMPOS, 1987). Estas águas são oriundas de aquífero regional do tipo livre, localmente semi-confinado, e de ocorrência associada à geologia da região.

Localizada na Bacia do Paraná, a região apresenta litologia composta de arenitos de granulação fina a média, combinados com arenitos siltosos, arenitos argilosos e delgadas lentes argilosas, onde localmente ocorrem cimento e nódulos carbonáticos, ainda preservados, da Formação Santo Anastácio, assente sobre a formação Serra Geral, que compreende derrames de basaltos toleíticos intercalados com arenitos (IPT, 1981). Esta formação contribui para a ocorrência de águas bi-carbonatadas, o que é corroborado pelas análises de água do córrego do Cinturão Verde, em Ilha Solteira - SP, onde Moura et al. (2013), encontraram valores para cálcio variando de 13 a $64 \mathrm{mg} \mathrm{L}^{-1}$, e magnésio variando de 12 a $74 \mathrm{mg} \mathrm{L}^{-1}$.

Cultura Agronômica, Ilha Solteira, v.24, n.4, p.343-354, 2015 
A irrigação com água acentuadamente calcária propicia altas concentrações de $\mathrm{HCO}^{3-}$ na solução do solo, $\mathrm{CaCO}_{3}$ precipitado, valores elevados de $\mathrm{pH}$ e ausência de $\mathrm{H}^{+}$e $\mathrm{Al}^{3+}$ trocáveis (LINDSAY, 1979; SO; AYLMORE, 1995).

Ao utilizar água do abastecimento público para irrigar experimentos, nos quais a água de irrigação não precisa ser purificada, introduz-se no solo elementos químicos que podem comprometer a qualidade dos resultados produzidos, uma vez que solos submetidos a cultivos irrigados podem sofrer modificações químicas, físicas e biológicas, podendo essas modificações variar dependendo da qualidade e quantidade de água aplicada (FARIA et al., 2009).

$\mathrm{O}$ conceito de qualidade da água refere-se às características que podem afetar sua adaptabilidade para uso específico, no caso da irrigação levam-se em consideração as características químicas e físicas (AYERS; WESTCOT, 1999), sendo o efeito da composição e concentração dos sais dissolvidos na água, sobre os solos irrigados, de grande importância para manutenção da fertilidade do solo (CAVALCANTE, 2000; CORDEIRO, 2001).

Deste modo, a avaliação da qualidade da água para rega de experimentos é muito importante particularmente para os conduzidos em vasos, pois pode comprometer os resultados se não for devidamente considerada e adequadamente controlada. Dentro deste contexto objetivou-se avaliar as alterações no $\mathrm{pH}, \mathrm{P}, \mathrm{K}^{+}, \mathrm{Ca}^{2+}, \mathrm{Mg}^{2+} \mathrm{e} \mathrm{H}+\mathrm{Al}$ do solo, em experimento conduzido em vasos, em condições protegidas, após molhamento com água de abastecimento público.

\section{MATERIAL E MÉTODOS}

O experimento foi conduzido durante oito meses (2011), em condição de cultivo protegido, em Latossolo Vermelho Distrófico típico, de textura argilosa, fase cerrado, coletado no Município de Selvíria-MS (20²0’ 13” S, 51 24'36” O), na profundidade de 00,20 m, sob Cerrado conservado.

O solo foi analisado quanto a fertilidade (RAIJ et al., 2001) e textura (EMBRAPA, 2011) antes da instalação do experimento, sendo os resultados apresentados na Tabela 1.

O solo para instalação do experimento foi peneirado $(2 \mathrm{~mm})$ e acondicionado em vasos (2L), onde foram acomodados $1,2 \mathrm{~kg}$ de solo. Este foi molhado manualmente, três vezes por semana de 21/03 a 25/04/2011 e duas vezes por semana de 25/04 a 21/11/11, sempre em dias alternados.

O experimento foi conduzido em um delineamento experimental inteiramente casualizado, em esquema fatorial $(2 \times 4 \times 4)$ sendo 2 tipos de água, 4 quantidades de água e 4 períodos de irrigação, com três repetições, totalizando 96 unidades experimentais.

$\mathrm{O}$ molhamento foi conduzido com dois tipos de água: purificada (PR), em deionizador, e água fornecida pelo setor de abastecimento público (AP) do município de Ilha Solteira - SP; quatro quantidades diferentes de água por molhamento (0, 200, 400 e 600 
$\mathrm{mL}$ ), que foram transformadas, a partir da área do vaso, em equivalente a mm de lâmina d'água (Tabela 2) e quatro períodos de irrigação (60; 120; 180 e 240 dias de irrigação). O experimento contou com manutenção diária para evitar o crescimento espontâneo de vegetação.

Tabela 1. Caracterização inicial do solo utilizado.

\begin{tabular}{ccc}
\hline \multicolumn{3}{c}{ Resultados Analíticos } \\
\hline Parâmetro & Umidade & Resultado \\
\hline $\mathrm{pH}\left(\mathrm{CaCl}_{2}\right)$ & -- & 5,5 \\
$\mathrm{MO}$ & $\mathrm{g} \mathrm{dm}^{-3}$ & 22 \\
$\mathrm{P}$ & $\mathrm{mg} \mathrm{dm}^{-3}$ & 19 \\
$\mathrm{~K}^{+}$ & $\mathrm{mmol}_{\mathrm{c}} \mathrm{dm}^{-3}$ & 3,7 \\
$\mathrm{Ca}^{2+}$ & $\mathrm{mmol}_{\mathrm{c}} \mathrm{dm}^{-3}$ & 20 \\
$\mathrm{Mg}^{2+}$ & mmol $_{\mathrm{c}} \mathrm{dm}^{-3}$ & 19 \\
$\mathrm{H}+\mathrm{Al}$ & mmol $_{\mathrm{c}} \mathrm{dm}^{-3}$ & 28 \\
$\mathrm{Al}$ & $\mathrm{mmol}_{\mathrm{c}} \mathrm{dm}^{-3}$ & 0 \\
$\mathrm{SB}$ & $\mathrm{mmol}_{\mathrm{c}} \mathrm{dm}^{-3}$ & 42,7 \\
$\mathrm{CTC}$ & $\mathrm{mmol}_{\mathrm{c}} \mathrm{dm}^{-3}$ & 70,7 \\
$\mathrm{~V}$ & $\%_{0}$ & 60 \\
Areia & $\mathrm{g} \mathrm{kg}^{-1}$ & 263 \\
Silte & $\mathrm{g} \mathrm{kg}^{-1}$ & 147 \\
Argila & $\mathrm{g} \mathrm{kg}^{-1}$ & 590 \\
\hline
\end{tabular}

Tabela 2. Valores estimados de lâmina d'água $(\mathrm{mm})$, relacionados à área de molhamento $\left(0,005 \mathrm{~m}^{2}\right)$ e aos valores adicionados de água (VAA), ao longo do período experimental, em condições controladas.

\begin{tabular}{ccccc}
\hline \multirow{2}{*}{ VAA } & \multicolumn{4}{c}{ Período de rega ou molhamento (dias) } \\
\cline { 2 - 4 } & 60 & 120 & 180 & 240 \\
\hline $\mathrm{mL}$ & ---- & --- & $\mathrm{mm}--------$ \\
200 & 920 & 1640 & 2360 & 3080 \\
400 & 1840 & 3280 & 4720 & 6120 \\
600 & 2760 & 4920 & 7080 & 9240 \\
\hline
\end{tabular}

Análises de fertilidade do solo foram realizadas a cada 60 dias durante o período experimental (240 dias), totalizando quatro avaliações, que tiveram todo o solo da unidade experimental homogeneizado para retirada da amostra, sendo o restante descartado.

A água fornecida pelo setor de abastecimento do município de Ilha Solteira - SP, foi analisada quanto a concentração de $\mathrm{Ca}^{2+}, \mathrm{Mg}^{2+}$ e $\mathrm{P}$, com avaliação de quatro amostras de água coletadas a cada 4 dias, sendo $\mathrm{Ca}^{2+} \mathrm{e} \mathrm{Mg}^{2+}$ analisados de acordo com Vanzela (2004) e $\mathrm{P}$ de acordo com Apha (1992), onde $\mathrm{Ca}^{2+}=81 \mathrm{mg} \mathrm{L}^{-1}, \mathrm{Mg}^{2+}=29 \mathrm{mg} \mathrm{L}^{-1}$ e $\mathrm{P}=1,19 \mathrm{mg} \mathrm{L}^{-1}$.

Os dados foram submetidos à análise da variância (ANAVA), teste de Tukey a 5\% de probabilidade para comparação de medias em relação ao tipo de água aplicada e regressão para avaliação do período de irrigação e das quantidades de água utilizadas. Os resultados 
foram analisados estatisticamente com uso do programa SISVAR (FERREIRA, 2011).

\section{RESULTADOS E DISCUSSÃO}

A água fornecida pelo abastecimento público (AP) quando utilizada no molhamento do experimento, alterou as condições de fertilidade do solo (Tabela 3). Os valores de $\mathrm{P}, \mathrm{pH}$, $\mathrm{Ca}^{2+}$ e $\mathrm{Mg}^{2+}$ do solo apresentaram incrementos quando foi utilizada a água de AP, se comparado com a utilização de água purificada em deionizador (PR). Tanto na presença de água do $\mathrm{AP}$ como de água $\mathrm{PR}$, os teores de $\mathrm{K}^{+}$do solo foram reduzidos em relação à média inicial $\left(\mathrm{K}^{+}=3,7 \mathrm{mmol}_{\mathrm{c}} \mathrm{dm}^{-3}\right)$ e apresentaram valores muito próximos nos dois tipos de água utilizados, embora estatisticamente possam ser considerados distintos (Tabela 3).

Tabela 3. Médias de $\mathrm{P}, \mathrm{pH}, \mathrm{K}^{+}, \mathrm{Ca}^{2+}, \mathrm{Mg}^{2+}$ e acidez potencial $(\mathrm{H}+\mathrm{Al})$, probabilidade de $\mathrm{F}$ e coeficiente de variação (CV) para tipos de água, quantidade de água e período de molhamento do solo, em condições controladas.

\begin{tabular}{|c|c|c|c|c|c|c|}
\hline Fontes de & $\mathbf{P}$ & pH & $\mathbf{K}^{+}$ & $\mathrm{Ca}^{2+}$ & $\mathrm{Mg}^{2+}$ & $\mathbf{H}+\mathbf{A l}$ \\
\hline Variação & $\mathrm{mg} \mathrm{dm}^{-3}$ & $\mathrm{CaCl}_{2}$ & \multicolumn{4}{|c|}{$\ldots$} \\
\hline \multicolumn{7}{|c|}{ Tipo de água (AG) } \\
\hline AP & $21,58 \mathrm{a}$ & $5,71 \mathrm{a}$ & $3,23 b$ & $26,19 a$ & $23,10 \mathrm{a}$ & $24,71 b$ \\
\hline PR & $20,00 \mathrm{~b}$ & $5,48 b$ & $3,36 \mathrm{a}$ & $22,27 b$ & $20,35 b$ & $27,67 \mathrm{a}$ \\
\hline \multicolumn{7}{|c|}{ Quantidade de água em mL (QT) } \\
\hline 000 & 18,33 & 5,45 & 4,10 & 22,62 & 19,87 & 28,12 \\
\hline 200 & 21,21 & 5,59 & 3,32 & 23,58 & 22,00 & 26,42 \\
\hline 400 & 21,63 & 5,67 & 2,97 & 24,75 & 22,08 & 25,29 \\
\hline 600 & 22,00 & 5,66 & 2,80 & 25,96 & 22,96 & 24,92 \\
\hline \multicolumn{7}{|c|}{ Período de molhamento em dias (PI) } \\
\hline 60 & 18,63 & 5,60 & 3,46 & 23,75 & 19,04 & 26,75 \\
\hline 120 & 21,29 & 5,58 & 3,46 & 22,25 & 21,58 & 26,96 \\
\hline 180 & 21,96 & 5,52 & 3,21 & 24,33 & 22,25 & 26,67 \\
\hline 240 & 22,29 & 5,68 & 3,06 & 26,58 & 24,04 & 24,37 \\
\hline \multicolumn{7}{|l|}{ Valor de $\mathbf{F}$} \\
\hline $\mathrm{AG}$ & $66,391^{* *}$ & $120,817^{* *}$ & $11,726^{* *}$ & $77,339^{* *}$ & $81,042^{* *}$ & $135,329^{* *}$ \\
\hline QT & $73,900^{* *}$ & $23,943^{* *}$ & $250,593^{* *}$ & $10,506^{* *}$ & $18,388^{* *}$ & $32,081^{* *}$ \\
\hline PI & $63,755^{* *}$ & $10,667^{* *}$ & $29,398^{* *}$ & $16,301^{* *}$ & $45,947^{* *}$ & $22,801^{* *}$ \\
\hline AGxQT & $4,874^{* *}$ & $26,796^{* *}$ & $8,148^{* *}$ & $12,318^{* *}$ & $0,682^{\mathrm{ns}}$ & $22,201^{* *}$ \\
\hline AGxPI & $26,483^{* *}$ & $27,226^{* *}$ & $2,562^{\mathrm{ns}}$ & $20,668^{* *}$ & $24,273^{* *}$ & $42,210^{* *}$ \\
\hline QTxPI & $4,036^{* *}$ & $2,476^{*}$ & $5,564^{* *}$ & $1,590^{\mathrm{ns}}$ & $2,913^{* *}$ & $3,081^{* *}$ \\
\hline AGxQTxPD & $7,510^{* *}$ & $6,380^{* *}$ & $3,153^{* *}$ & $9,245^{* *}$ & $8,112^{* * *}$ & $8,212^{* *}$ \\
\hline $\mathrm{CV}(\%)$ & 5 & 2 & 5 & 9 & 7 & 5 \\
\hline
\end{tabular}

Médias seguidas de mesma letra, nas colunas, por fonte de variação, não diferem significativamente entre si pelo teste de Tukey a $5 \%$. ${ }^{\mathrm{ns}}=$ valores não significativos; ${ }^{* *} \mathrm{e}{ }^{*}=$ valores significativos para $\mathrm{P} \leq 0,01 \mathrm{e} \leq 0,05$, respectivamente. $\mathrm{AG}=$ Tipo de Água; $\mathrm{AP}=$ Água de Abastecimento Público; $\mathrm{PR}=$ Água purificada em deionizador; $\mathrm{QT}=$ Quantidade de água $(\mathrm{mL}) ; \mathrm{PI}=$ Período de molhamento ou rega (dias).

Cultura Agronômica, Ilha Solteira, v.24, n.4, p.343-354, 2015 
É possível verificar, ao analisar o desdobramento da interação tipo x quantidade de água (Figura 1) que o tipo de água interferiu na fertilidade do solo. A influência da água de $\mathrm{AP}$ foi maior para $\mathrm{P}, \mathrm{pH}, \mathrm{Ca}^{+} \mathrm{e} \mathrm{Mg}^{+2}$ e $\mathrm{H}+\mathrm{Al}$, em relação à água $\mathrm{PR}$, que não alterou o teor de $\mathrm{Ca}^{+2}$ e o $\mathrm{pH}$ do solo. As variações observadas permitem afirmar que a água de AP introduziu $\mathrm{P}, \mathrm{Ca}^{2+}$ e $\mathrm{Mg}^{2+}$ no solo, os dois últimos muito provavelmente na forma de carbonatos, contribuindo para elevar o $\mathrm{pH}$ e o $\mathrm{P}$, reduzindo o $\mathrm{H}+\mathrm{Al}$. Os incrementos no $\mathrm{pH}$ podem interromper o processo de fixação de $\mathrm{P}$, reduzindo a adsorção do mesmo e promovendo incrementos deste no solo (NOVAIS; SMYTH, 1999), não deixando de citar que, embora em pequenas quantidades, pode ter sido também adicionado pela água de AP $\left(1,19 \mathrm{mg} \mathrm{L}^{-1}\right.$ de P).
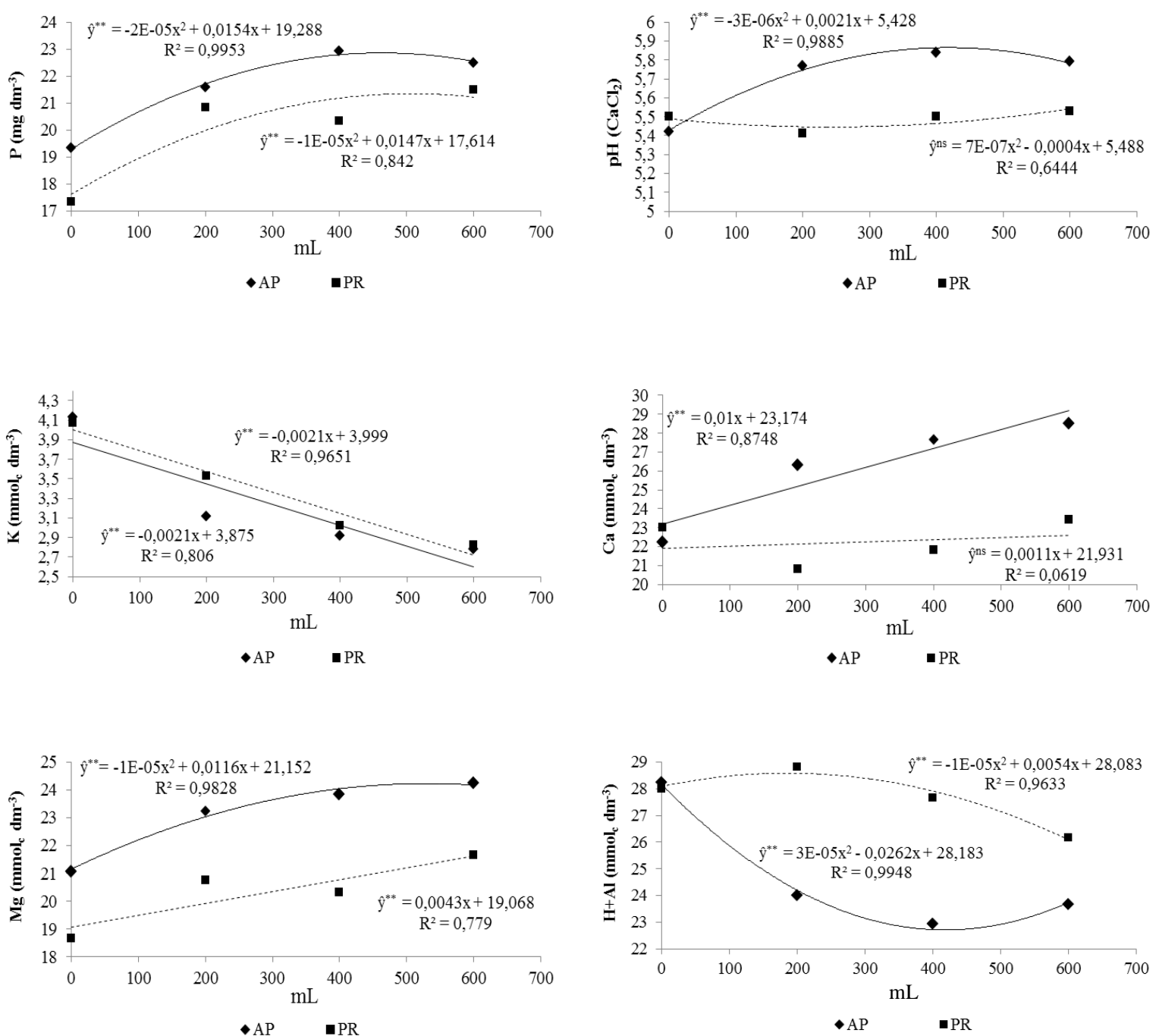

${ }^{\mathrm{ns}}=$ valores não significativos; ${ }^{* *} \mathrm{e}$ * $=$ valores significativos para $\mathrm{P} \leq 0,01 \mathrm{e} \leq 0,05$, respectivamente. $\mathrm{AG}=\mathrm{Tipo}$ de Água; AP=Água de Abastecimento Público; $\mathrm{PR}=$ Água purificada em deionizador; $\mathrm{QT}=$ Quantidade de água (mL); PI= Período de molhamento (dias).

Figura 1. Desdobramentos da interação entre tipo de água utilizada e quantidade de água aplicada no molhamento, em condições controladas, para $\mathrm{P}, \mathrm{pH}, \mathrm{K}^{+}, \mathrm{Ca}^{2+}, \mathrm{Mg}^{2+} \mathrm{e} \mathrm{H}+\mathrm{Al}$.

Maia et al. (2001) também relataram aumentos nos valores de $\mathrm{pH}$ dos solos, ao longo do tempo, em áreas irrigadas com água com teores de carbonato de cálcio em torno de 2,70 
$\mathrm{mmol}_{\mathrm{c}} \mathrm{dm}^{-3}$, na região da Chapada do Apodi - RN. Aumentos em $\mathrm{Ca}^{2+}$ para Latossolos e Neossolos foram relatados por Garcia et al. (2008) utilizando água salina. Os autores não verificaram alterações na disponibilidade de $\mathrm{K}^{+}, \mathrm{Mg}^{2+}$ e $\mathrm{H}+\mathrm{Al}$.

Quanto ao período de irrigação, é importante considerar que as características da água podem sofrer variações ao longo do ano, apresentando, segundo Almeida (2010), maior concentração em sais no período mais seco e o oposto no período chuvoso, o que pode ter contribuído para o comportamento quadrático observado, para $\mathrm{Ca}^{2+}, \mathrm{pH}, \mathrm{P} \mathrm{e} \mathrm{H}+\mathrm{Al}$ (Figura

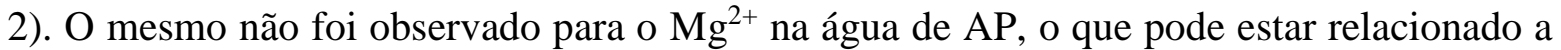
uma menor variação deste elemento entre período chuvoso e seco, como relatam Franco e Hernandez (2009), o que está relacionado à geologia da região que permite o maior aporte de $\mathrm{Ca}^{2+}$ à água.
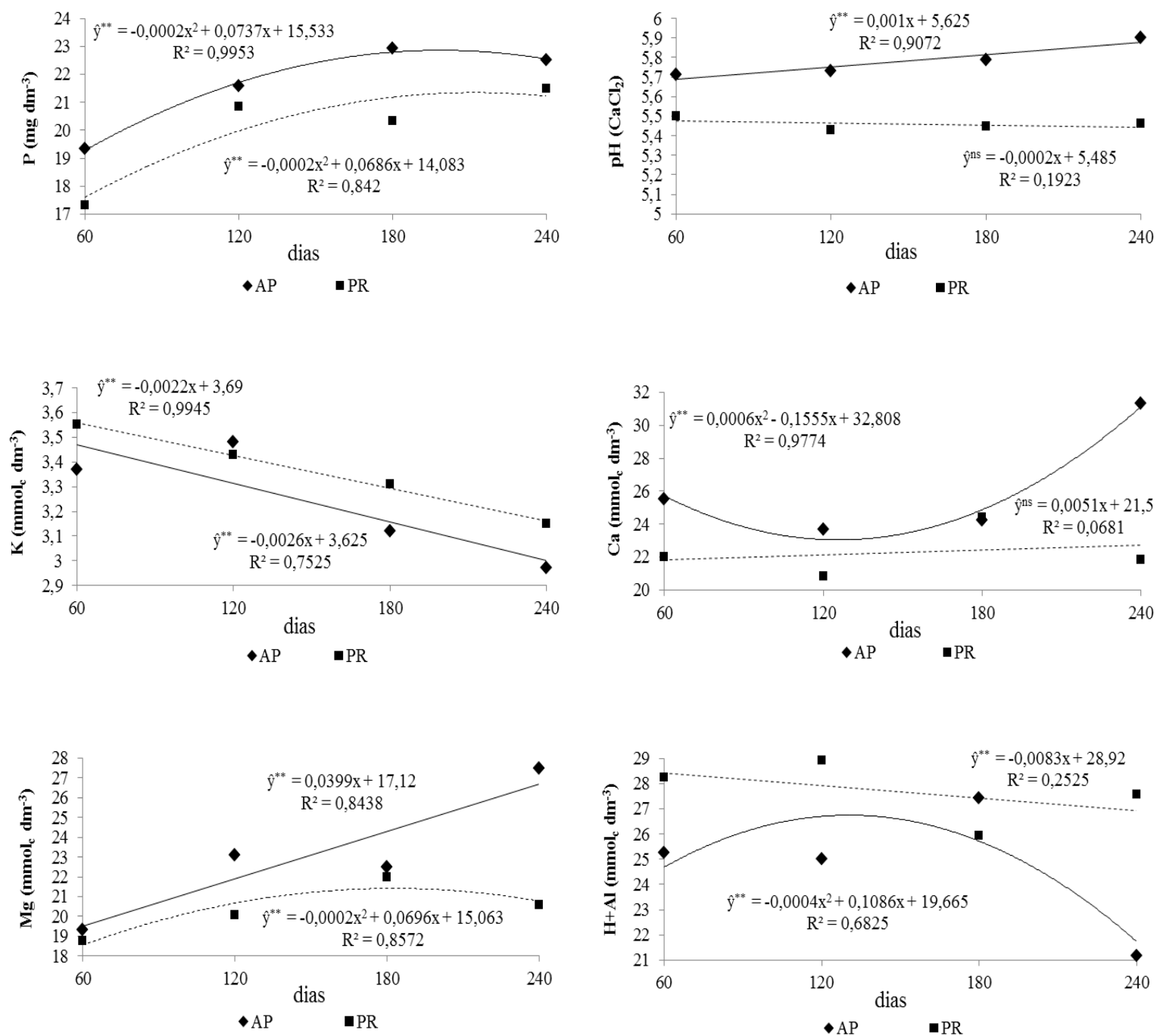

ns $=$ valores não significativos; ${ }^{* *} \mathrm{e}^{*}=$ valores significativos para $\mathrm{P} \leq 0,01 \mathrm{e} \leq 0,05$, respectivamente. $\mathrm{AG}=$ Tipo de Água; AP =Água de Abastecimento Público; PR = Água purificada em deionizador; $\mathrm{QT}=$ Quantidade de água $(\mathrm{mL}) ; \mathrm{PI}=$ Período de molhamento (dias).

Figura 2. Desdobramentos da interação entre tipo de água utilizada e período de irrigação, aplicada no molhamento, em condições controladas, para $\mathrm{P}, \mathrm{pH}, \mathrm{K}^{+}, \mathrm{Ca}^{2+}, \mathrm{Mg}^{2+} \mathrm{e} \mathrm{H}+\mathrm{Al}$.

Os teores de $\mathrm{Ca}^{2+}$ e $\mathrm{Mg}^{2+}$ do solo aumentaram quando se utilizou água de $\mathrm{AP}$,

Cultura Agronômica, Ilha Solteira, v.24, n.4, p.343-354, 2015 
comparada à água PR (Tabela 3). Comportamento que se acentua com os incrementos na quantidade de água e ao longo do tempo (Figuras 1 e 2), sugerindo que os incrementos se sobrepõem a uma possível lixiviação, e são atribuídos à água utilizada, que contém $81 \mathrm{mg} \mathrm{L^{- }}$ ${ }^{1}$ de $\mathrm{Ca}^{2+}$ e $29 \mathrm{mg} \mathrm{L}^{-1}$ de $\mathrm{Mg}^{2+}$.

Com relação à água $\mathrm{PR}$ verifica-se ausência de alterações nos teores de $\mathrm{Ca}^{2+}$ do solo relacionado tanto à quantidade de água aplicada quanto ao período de molhamento (Figuras

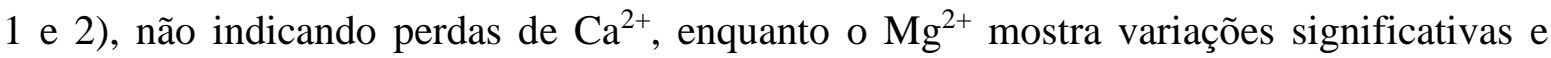
positivas, porém tão pequenas que não cabe destacar (Figuras 1 e 2). Ao conduzir experimentos em vaso, além da atenção destinada à qualidade da água, os processos de lixiviação também precisam ser evitados.

$\mathrm{O} \mathrm{K} \mathrm{K}^{+}$apresentou comportamento indicativo de lixiviação, com decréscimo em seus teores para os dois tipos de água utilizados. Kolahchi e Jalali (2007) constataram maior lixiviação de $\mathrm{K}^{+}$quando a água utilizada estava enriquecida em $\mathrm{Ca}^{2+}$, que tem maior habilidade para deslocar o $\mathrm{K}^{+}$dos sítios de troca, colocando este em solução e facilitando a lixiviação, enfatizando o efeito da qualidade da água sobre este processo. Os efeitos relacionados à quantidade de $\mathrm{Ca}^{2+}$ na água sobre a lixiviação do $\mathrm{K}^{+}$não ficam claros neste trabalho.
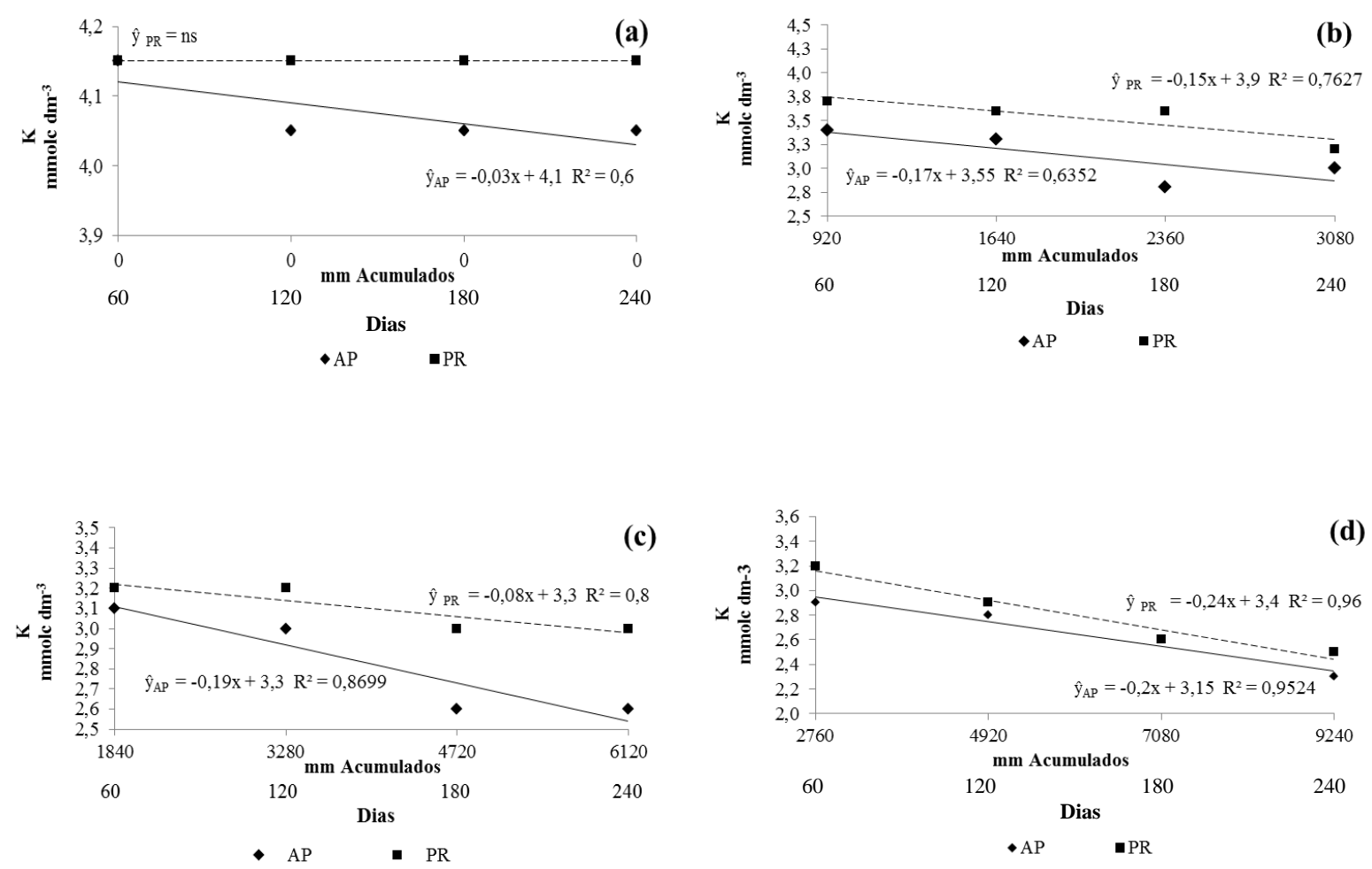

AP = Água de Abastecimento Público de Ilha Solteira (SP); PR = Água Purificada em deionizador.

Figura 3. Comportamento do $\mathrm{K}^{+}$frente à quantidade de água percolada (equivalente em $\mathrm{mm}$ de lâmina d'água) ao longo do período experimental em dias. 
A lixiviação do $\mathrm{K}^{+}$foi acentuada com o aumento da quantidade de água utilizada $(2,82$ $\mathrm{mmol}_{\mathrm{c}} \mathrm{dm}^{-3}$ no solo com $600 \mathrm{~mL}$ ) e não apresentou diferenças significativas entre tipos de água (Figura 2). Esta observação indica que a lixiviação deste nutriente não foi influenciada pelo $\mathrm{Ca}^{2+}$, sugerindo que a concentração de $\mathrm{Ca}^{2+}$ na água de abastecimento público (81 mg $\mathrm{L}^{-1}$ ) não foi suficiente para deslocar o $\mathrm{K}^{+}$dos sítios de troca. Entretanto, a lixiviação do $\mathrm{K}^{+}$ se acentua ao longo do tempo, sendo reduzido a 2,3 e $2,5 \mathrm{mmol} \mathrm{dm}^{-3}$ no solo com $600 \mathrm{~mL}$, para AP e PR, respectivamente, aos 240 dias, permitindo inferir que 32 a $38 \%$ do $\mathrm{K}^{+}$do solo foi lixiviado nesta condição extrema, isto é, $9.240 \mathrm{~mm}$ de lâmina d'água (Figura 3).

Com relação à quantidade de água adicionada (Figura 3d), pode-se inferir que na ausência da adição de $\mathrm{K}^{+}$ao solo, numa região com precipitação média anual de $1.155 \mathrm{~mm}$, após 8 anos, isto é, após $9.240 \mathrm{~mm}$ de precipitação, o solo pode perder até $38 \%$ do $\mathrm{K}^{+}$, se não ocorressem acréscimos via matéria orgânica ou insumos. Portanto, a manutenção do $\mathrm{K}^{+}$ no solo se dá via matéria orgânica, principalmente em regiões de solos bastante intemperizados, onde não há minerais como fonte de $\mathrm{K}^{+}$para o solo.

Ao se avaliar o comportamento do $\mathrm{K}^{+}$ao longo do período experimental nota-se que ocorre redução do mesmo ao longo do tempo, para as duas fontes de água (Figura 4), o que está relacionado à maior quantidade de água que percola no sistema, e está em acordo com os achados de Albuquerque et al. (2011).
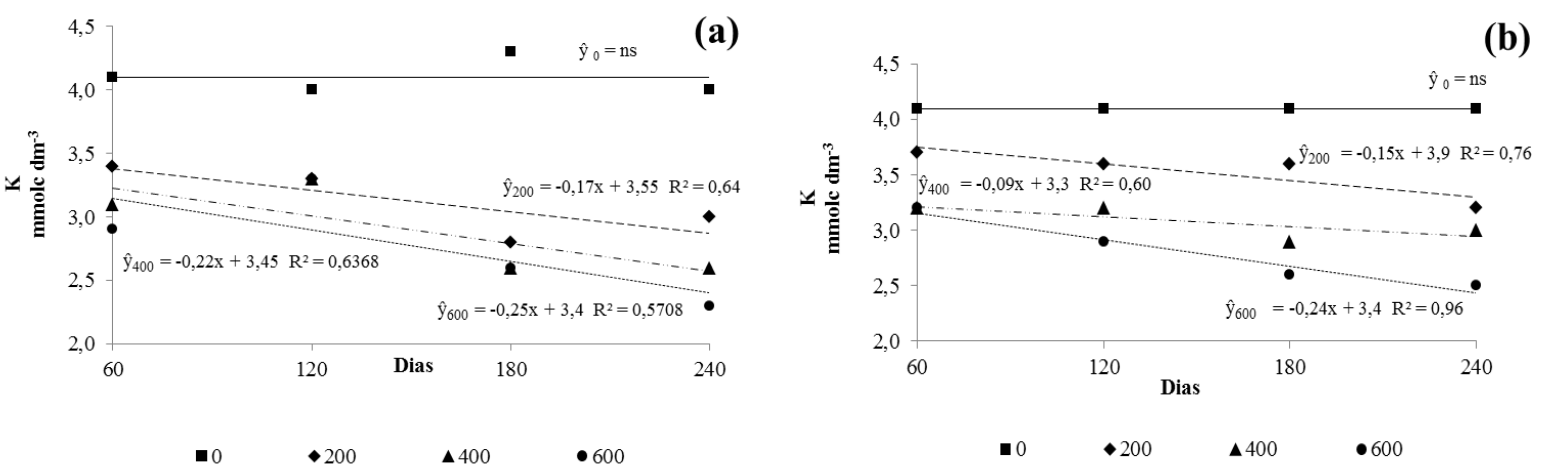

Figura 4. Comportamento do $\mathrm{K}^{+}$ao longo do período experimental para (a) = Água de Abastecimento Público - AP e (b) = Água Purificada - PR, ao longo do tempo e nas diferentes quantidades aplicadas. Onde, 0; 200; 400 e $600=\mathrm{mL}$ de água aplicada.

\section{CONCLUSÃO}

A água de abastecimento público produziu incrementos em $\mathrm{P}, \mathrm{Ca}^{2+}, \mathrm{Mg}^{2+}$ e $\mathrm{pH}$ do solo, e reduziu a acidez potencial $(\mathrm{H}+\mathrm{Al})$.

$\mathrm{O} \mathrm{K}^{+}$do solo foi lixiviado nas duas condições de água utilizadas. 


\section{REFERÊNCIAS BIBLIOGRÁFICAS}

ALFARO, M. A.; GREGORY, P. J.; JARVIS, S. C. Dynamics of potassium leaching on a hill slope grassland soil. Journal of Envionment Quality, Madison, v. 33, n. 1, p.192-200, 2004.

ALBUQUERQUE, F. S.; SILVA, E. F. F.; SOUZA, A. M. R.; ROLIM, M. M. Lixiviação de potássio em um cultivo de pimentão sob lâminas de irrigação e doses de potássio. Revista Caatinga, Mossoró, v. 24, n. 3, p.135-144, 2011.

ALMEIDA, O. A. Qualidade da água de irrigação. Cruz das Almas: Embrapa Mandioca e Fruticultura, 2010. 234 p.

APHA. Standard methods for the examination of water and waste Waters. New York: American Public Health Association, 1992.18 ed. 1193 p.

AYERS, R. S.; WESTCOT, D. W. A qualidade da água na agricultura. Campina Grande: UFPB, 1999. 153 p. (Estudos FAO: Irrigação e Drenagem, 29).

CAMPOS, H. C. N. S. Contribuição do estudo hidrogeoquímico do Grupo Bauru no Estado de São Paulo. 1987. 158 p. Dissertação (Mestrado em Geologia Geral e de Aplicação) - Instituto de Geociências, Universidade de São Paulo, São Paulo, 1987.

CAVALCANTE, L. F. Sais e seus problemas nos solos irrigados. Areia: UFPB, 2000. 71 p.

CHUNG, S. O.; KANG, S.W.; BAE. K. S; RYU, M. J.; KIM, Y. J. The potential of remote monitoring and control of protected crop production environment using mobile phone under 3G and Wi-Fi communication conditions. Engineering in Agriculture, Environment and Food, Amsterdam, 2015. Disponível em: http://www.sciencedirect.com/science/article/pii/S1881836615000300. Acesso em: 20 out. 2015.

CORDEIRO, G. G. Qualidade de água para fins de irrigação: conceitos e práticas. Petrolina: Embrapa Semi-árido, 2001. 32 p.

EMBRAPA. Centro Nacional de Pesquisa de Solos. Manual de métodos de análise de solo. 2. ed. Rio de Janeiro: Embrapa Solos, 2011. 225 p.

FARIA, F. H. S.; LIMA, L. A.; RIBEIRO, M. S.; SANTOS, S. R.; RIBEIRO.K. M. Avaliação da salinidade, sodicidade e alcalinidade das águas subterrâneas para irrigação em Jaíba e Janaúba, Minas Gerais. Irriga, Botucatu, v. 14, n. 3, p.299-313, 2009.

Cultura Agronômica, Ilha Solteira, v.24, n.4, p.343-354, 2015 
FERREIRA, D. F. Sisvar: a computer statistic analysis system. Ciência e Agrotecnologia, Lavas, v. 35, n. 6, p.1039-1042, 2011.

FRANCO, R. A. M.; HERNANDEZ, F. B. T. Qualidade da água para irrigação na microbacia do Coqueiro, Estado de São Paulo. Revista Brasileira de Engenharia Agrícola e Ambiental, Campina Grande, v. 13, n. 6, p.772-780, 2009.

GARCIA, G. O.; MARTINS-FILHO, S.; REIS, E. F; MORAES, W. B.; NAZÁRIO, A. A. Alterações químicas de dois solos irrigados com água salina. Revista Ciência Agronômica, Fortaleza, v. 39, n. 1, p.7-18, 2008.

ILHA SOLTEIRA. Tratamento da Água de Ilha Solteira. Disponível em: http://www.ilhasolteira.sp.gov.br/index.php?option=com_content\&view=article\&id=1\&Ite mid=277. Acesso em: 22 ago. 2015.

IPT - INSTITUTO DE PESQUISAS TECNOLÓGICAS. Mapa Geológico do Estado de São Paulo. Escala: 1:500.000. São Paulo: IPT, 1981. 126 p. (Monografias, n. 6).

KOLAHCHI, Z.; JALALI, M. Effect of water quality on the leaching of potassium from sandy soil. Journal of Arid Environments, London, v. 68, n. 4, p.624-639, 2007.

LAGE, R. Plasticultura e cultivo protegido: informação e planejamento são indispensáveis. Revista Casa da Agricultura, Campinas, v. 14, n. 2, p.7-9, 2011.

LINDSAY, W. L. Chemical equilibrium in soils. New York: John Wiley, 1979. 449 p.

MAIA, C. E.; MORAIS, E. R. C.; OLIVEIRA, M. Estimativa de carbonato de cálcio aplicado via água de irrigação nas regiões da Chapada do Apodi e Baixo Açu, RN. Revista Brasileira de Engenharia Agrícola e Ambiental, Campina Grande, v. 5, n. 1, p.71-75, 2001.

MOURA, R. S.; HERNANDEZ, F. B. T.; LEITE, M. A.; FRANCO, R. A. M.; FEITOSA, D. G.; MACHADO, L. F. Qualidade da água para uso em irrigação na microbacia do córrego do cinturão verde, município de Ilha Solteira. Revista Brasileira de Agricultura Irrigada, Fortaleza, v. 5, n. 1, p.68-74, 2013.

NOVAIS, R. F.; SMYTH, T. J. Fósforo em Solo e Planta em Condições Tropicais. Viçosa: UFV / DPS, 1999. 399 p.

RAIJ, B. van; ANDRADE, J. C.; CANTARELlA, H.; QUAGGIO, J. A. Análise química para avaliação da fertilidade de solos tropicais. Campinas: Instituto Agronômico, 2001. $284 \mathrm{p}$.

Cultura Agronômica, Ilha Solteira, v.24, n.4, p.343-354, 2015 
ROSOlEM, C. A.; GARCIA, R. A.; FOLONI, J. S. S.; CALONEGO, J. C. Lixiviação de potássio no solo de acordo com suas doses aplicadas sobre palha de milheto. Revista Brasileira de Ciência do Solo, Viçosa, v. 30, n. 5, p.813-819, 2006.

SILVA, B. A.; SILVA, A. R.; PAGIUCA, L. G. Cultivo Protegido: em busca de mais eficiência produtiva. Revista Hortifruti Brasil, Piracicaba, v. 12, n. 132, p.10-18, 2014.

SO, H. B.; AYLMORE, L. A. G. The effects of sodicity on soil physical behaviour. In: NAIDU, R.; SUMNER, M. E.; RENGASAMY, P. (eds.). Australian sodic soils: distribution, properties and management. East Melbourne: CSIRO, 1995. Cap. 3.1, p. 71-80.

VANZELA, L. S. Qualidade de água para irrigação na microbacia do córrego Três Barras no município de Marinópolis, SP. 2004. 96 p. Dissertação (Mestrado em Agronomia) - Faculdade de Engenharia, Universidade Estadual Paulista, Ilha Solteira, 2004. 